Loth S. Mulungu*, Victoria Ngowo, Mashaka E. Mdangi, Abdul S. Katakweba, Protas Tesha, Furaha P. Mrosso, Margaret Mchomvu, Apia W. Massawe, Ara Monadjem, Bukheti Kilonzo and Steven R. Belmain

\title{
Survival and recruitment of the multimammate mouse, Mastomys natalensis (Smith 1834), in a rice agro-ecosystem
}

\begin{abstract}
We investigated the recruitment and survival of the multimammate mouse, Mastomys natalensis, within irrigated rice and fallow field habitats at different time periods related to rice crop growth stages. Capture-MarkRecapture data were collected for $M$. natalensis each month from June 2010 to May 2012, and both recruitment and survival were estimated in relation to land use (irrigated rice or fallow field) within the agro-ecosystem. Higher recruitment and survival were observed in rice fields than in fallow fields suggesting the relationship was compensatory when there was a higher quality food resource. In terms of management, farmers in the study area should implement management strategies in rice fields at both transplanting and maturity stages of crop growth in order to maintain recruitment and survival at low levels.
\end{abstract}

Keywords: agriculture; pest management; population dynamics; rice cropping; rodent.

\footnotetext{
*Corresponding author: Loth S. Mulungu, Pest Management Centre, Sokoine University of Agriculture, P.O. Box 3110, Morogoro, Tanzania, e-mail: lothmulungu@yahoo.co.uk

Victoria Ngowo and Protas Tesha: Rodent Control Centre, Ministry of Agriculture, Food Security and Cooperatives, P.O. Box 3047, Morogoro, Tanzania

Mashaka E. Mdangi: MATI-Ilonga, Box 66, Kilosa, Morogoro, Tanzania
}

Abdul S. Katakweba, Apia W. Massawe and Bukheti Kilonzo: Pest Management Centre, Sokoine University of Agriculture, P.O. Box 3110, Morogoro, Tanzania

Furaha P. Mrosso: Ilonga Agricultural Research Institute P.O. Box 33 Kilosa, Morogoro, Tanzania

Margaret Mchomvu: Rodent Control Centre, Ministry of Agriculture, Food Security and Cooperatives, P.O. Box 3047, Morogoro, Tanzania; and Ilonga Agricultural Research Institute P.O. Box 33 Kilosa, Morogoro, Tanzania

Ara Monadjem: Department of Biological Sciences, University of Swaziland, Private Bag 4, Kwaluseni, Swaziland; and Mammal Research Institute, Department of Zoology and Entomology, University of Pretoria, Private Bag 20, Hatfield 0028, Pretoria, South Africa Steven R. Belmain: Natural Resources Institute, University of Greenwich, Kent ME4 4TB, UK
DOI 10.1515/mammalia-2014-0150

Received October 13, 2014; accepted January 27, 2015

\section{Introduction}

Rodents living in human-influenced landscapes have to cope with or adapt to the direct or indirect consequences of human activity. In addition, rodent pests are described as opportunistic species, characteristically conforming to an r-selected strategy when reproductive conditions are favourable (Leirs et al. 1997). Massawe et al. (2012) reported that interactions between humans and rodents can have detrimental effects on survival and recruitment. For example, in Tanzania, farmers produce rice crops twice per year in irrigated agro-ecosystems, one during the rainy season and another during the dry season exclusively under irrigation. Mulungu et al. (2013) reported that the population size of Mastomys natalensis, which is the major rodent pest in this environment, varied with habitat and by season. Populations were higher in fallow land compared with rice fields, and the highest population peak was observed during the dry season (July to October). Furthermore, individual rodents bred throughout the year but with a peak coinciding with crop maturity.

Despite some knowledge of the population dynamics and breeding patterns of Mastomys natalensis in rice agro-ecosystems (Mulungu et al. 2013), their survival and recruitment within this system is not well-known. Recruitment and survival can differ between agro-ecosystems as described by Massawe et al. (2005), who reported that recruitment and survival rates of $M$. natalensis were higher in slash-and-burn compared to tractor-ploughed maize fields. Similarly, Kennis et al. (2012) reported that survival of Deomys ferrugineus in primary forest was higher than in fallow land over a period of 4 weeks with increased survival potentially linked to higher abundance of the species main food resources, insects, and termites. 
The annual population cycle of Mastomys natalensis in maize-dominated crop fields is comprised of a population decline during the rainy season followed by a dry season increase (Leirs et al. 1994), where population growth patterns are associated with rainfall (Leirs et al. 1994, Massawe et al. 2011). Young animals' growth is inhibited at the end of the dry season (October-November), and growth is only resumed after the first heavy rains. This typical annual cycle of $M$. natalensis could reflect a decline due to a low survival rate of the first litters or a dilution of the population through dispersion into temporary habitats during the wet season followed by the return of individuals to fields in the early dry season (Leirs et al. 1994) or due to better habitat support for food, which will influence survival and earlier maturation (Leirs 1992). Thus, survival of $M$. natalensis is reported to be higher during the wet season, corresponding to the cropping season, whereas survival is low during the dry season arguably due to insufficient intake of food and increased competition (Massawe et al. 2012). High quality and abundant food during the wet season has been reported to result in faster growth and better survival for $M$. natalensis in maize cropping (Leirs et al. 1990). Similar studies on the recruitment and survival of $M$. natalensis in irrigated rice systems are lacking, and such knowledge is critical for the control of pest species as these factors determine whether the rate of control is sufficient to keep the population of the pest at low levels. Therefore, the aim of this study was to investigate the recruitment and survival of $M$. natalensis in an irrigated rice agro-ecosystem.

\section{Materials and methods}

\section{Study area}

This study was conducted at Hembeti village $\left(06^{\circ} 16^{\prime} \mathrm{S}\right.$, $37^{\circ} 31^{\prime} \mathrm{E}$ ), in Mvomero District, Morogoro, Tanzania. The study area has a bimodal rainfall pattern with short rains falling from October to December and long rains from March to June. Agricultural cropping patterns in Tanzania typically consist of a relatively small-scale matrix of agricultural fields and fallow land (Odhiambo et al. 2005). In this study area, some patches of fallow land exist within the irrigated rice ecosystem. Within fallow areas, the following plant species can be found in variable abundance: Black jack, Bidens pilosa (Compositae); Elephant grass, Pennistum purpureum (Gramineae); Guatemala grass, Tripsacum luxum (Gramineae); Nut grass, water grass, Cyperus rotundus (Cyperaceae); Cypperus esculentus
(Cyperaceae); Star grass, couch grass, Cynodon dactylon (Gramineae); Digitaria scalarum (Gramineae); Imperata cylindrica (Gramineae); and Water velvet, Azola africana (Salviniaceae). The average farm size in the study area is $0.5-1.5 \mathrm{ha}$, and farmers produce two rice crops per year. The first crop is planted during the wet season from January to June and the second one is during the dry season from July to December, exclusively dependent on irrigation. Land preparation and rice transplanting are conducted in January and July during the wet and dry seasons, respectively. The rice crops reach physiological maturity in May and November, and farmers harvest in June and December for wet and dry seasons, respectively. The booting stage is in April and October for wet and dry seasons, respectively. The rest of the cropping period, February-March for wet season and August-September for dry season, is the vegetative crop growth stage.

\section{Trapping rodents}

A Capture-Mark-Recapture (CMR) study was carried out from June 2010 to May 2012. Four $70 \times 70 \mathrm{~m}$ trapping grids, two in rice and two in fallow mosaic fields, were permanently established. The size of the grids corresponds with the approximate size of the farmer's field where the boundaries from one field to another were the bunds around the fields. A distance of $>300 \mathrm{~m}$ was set between each CMR grid. Each grid consisted of seven parallel lines, $10 \mathrm{~m}$ apart, and seven trapping stations per line, also $10 \mathrm{~m}$ apart (a total of 49 trapping stations/grid). One Sherman LFA live trap $(8 \times 9 \times 23 \mathrm{~cm}, \mathrm{H} . \mathrm{B}$. Sherman Traps Inc., Tallahassee, FL, USA) was placed at each trapping station, and all were set for three consecutive nights at intervals of 4 weeks for a total of 24 trapping sessions. Traps, baited with peanut butter mixed with maize bran/maize flour, were placed in the afternoon and inspected in the morning. During flooding, the traps were placed on top of dry grass clumps in grid locations.

\section{Captured animals}

Data presented in this study is focussed on Mastomys natalensis, which represented more than $95 \%$ of all captures. However, four other rodent species were also captured at the site, viz: Dasymys cf. incomtus, Rattus rattus, Grammomys dolichurus and Acomys cf. spinosissimus. Captured animals were treated in a humane manner and in compliance with the 1964 Helsinki Declaration (7th revision) and guidelines of the American Society of 
Mammalogists (Sikes and Gannon 2011). The research study also follows the ethical regulations of Sokoine University of Agriculture, and all procedures of acquiring permits from the local authority to carry out the studies in the designated area were strictly adhered to. All captured animals were taken to the field laboratory and identified to species level (Kingdon 1997). On the first day of capture, all animals were marked by toe clipping using an established coding system (Borremans et al. 2014). For each capture, the trap station was recorded along with the animal's sex, weight and reproductive condition (males were either scored as scrotal or non-scrotal and females as perforate or imperforate vagina, lactating or pregnant through palpation). The animals were then released at the same location of capture.

\section{Data collection and analysis}

\section{Recruitment}

We defined recruitment as the temporal measure of the proportion of new individuals brought into the population (Massawe et al. 2005). We estimated the rate of recruitment as the proportion of new individuals entering the trappable population during the entire study period. The number of unmarked animals out of the total capture for each trapping session was used to establish the proportion of new recruitment into the population. The proportions of new individuals were compared between months, crop growth stages and habitats employing a repeated measure analysis within a generalised linear model using the statistics programme Statistica (StatSoft, Inc., Tulsa, OK, USA).

\section{Survival}

As Mastomys natalensis was captured in high numbers during the study period, we were able to estimate species survival using the Cormack-Jolly-Seber (CJS) model (Lebreton et al.1992) using the software programme MARK (White and Burnham 1999, White 2008). The capture history $(\mathrm{CH})$ database consists of columns indicating each primary trapping session and rows for each individual capture history, where a zero entry indicates that an individual was not encountered in that particular month, and a one indicates it was encountered at least once in that trapping session (Pollock et al. 1990). A variety of models that included the factors of time, habitat (rice or fallow field), season (wet or dry season) and cropping stage (transplanting, vegetative, booting and harvesting) were tested for goodness-of-fit using the full CJS model with time-dependent survival $(c t)$ and recapture probabilities ( $p t)$. To test the main effects of different factors and their interactions, we used the software programme MARK (White and Burnham 1999, White 2008). To select the most appropriate model, we used the Akaike Information Criterion (AIC) corrected for the effective sample size (Lebreton et al. 1992): $\mathrm{AIC}=\mathrm{DEV}+2 k+2 k[n /(n-k-1)]$, where DEV represents the deviance $[-2 \ln (L)], L$ the likelihood of the model evaluated at maximum likelihood estimates, $k$ the number of separately estimated parameters in the model and $n$ the effective sample size. The models were ranked using the difference between the AIC of the model and the AIC of the best model (referred to as $\triangle \mathrm{AIC}$ ). $\triangle$ AIC can be interpreted according to this scale: models having $\triangle \mathrm{AIC} \leq 2$ are strongly plausible alternatives to the best model, those where $4 \leq \Delta \mathrm{AIC} \leq 7$ are considerably less plausible, whereas models having a $\triangle \mathrm{AIC} \geq 10$ are improbable (Burnham and Anderson 2002). In this case, for the sake of parsimony, we considered that the best model was the one with the fewest parameters. All mean values are quoted with \pm SE.

\section{Results}

\section{Recruitment of new individuals}

We hypothesized that variation in the recruitment of Mastomys natalensis is closely associated with varying conditions created in the environment through different habitats in irrigated rice agro-ecosystems. Over the study period, the month $\left(\mathrm{F}_{11,67}=543.60, \mathrm{p}=0.13\right)$ had no significant effect on the proportion of new individuals entering the trappable population, and there were no interactions between month and habitat $\left(\mathrm{F}_{11,67}=191.69, \mathrm{p}=0.55\right)$. However, the proportion of new individuals entering the trappable population differed significantly between habitats $\left(\mathrm{F}_{1,67}=11.47, \mathrm{p}=0.00\right)$ showing more individuals entering the trappable population in the rice fields (60.92) compared to fallow land (47.24) (Figure 1). Furthermore, it was observed that the proportion of new individuals entering the trappable population was higher during transplanting (mean $=0.62 \pm 0.05)$ and harvesting time (mean $=0.63 \pm 0.05$ ) compared with the booting stage (mean $0.45 \pm 0.05$ ) in both habitats (Figure 1). However, no significant difference was observed between the two seasons $\left(F_{1,60}=0.60, p=0.42\right)$, with the percentage recruitment of the dry season $=55.35$ and the wet season $=52.70, \operatorname{LSD}_{0.05}=6.50$. 


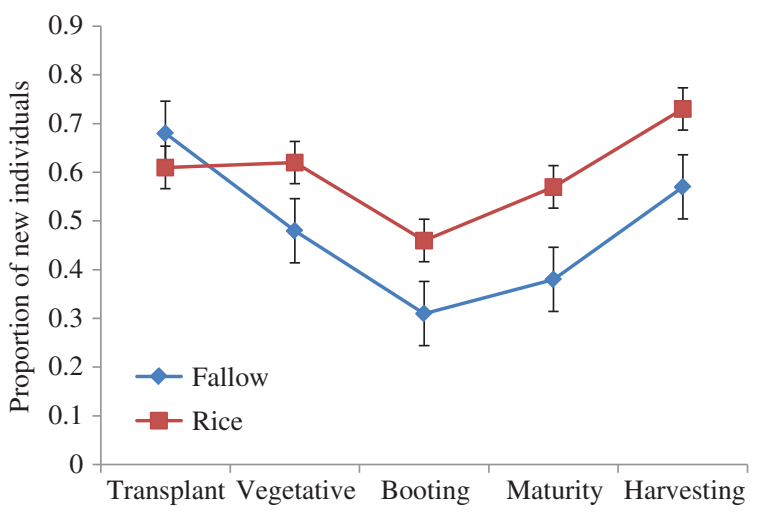

Figure 1: Proportion of new individuals entering the trappable population in the two habitats at different growth stages of rice crop.

\section{Survival}

The best model represented survival varying with habitat and cropping stage and recaptures varying with time (Table 1). However, the next best model, which differed by an AICc of 3.06, represented survival varying with habitat and time and recaptures varying with time (Table 1). There were no other competing models, and the next best model, which comprised survival varying with habitat, and recaptures varying with time, was not well supported (AICc weight=0.003) (Table 1). Based on the best model of survival varying with habitat and cropping stage, the monthly survival of Mastomys natalensis varied significantly over the study period, depending on the cropping stage and the type of habitat (Figure 2). The survival rate followed a similar trend from transplanting to harvesting in the two different habitats and, in general, was observed to be higher in the rice fields at all cropping stages compared with the fallow land (Figure 2). In the fallow land, the survival rate varied from 0.29 to 0.58 where the lowest survival rate was observed during the

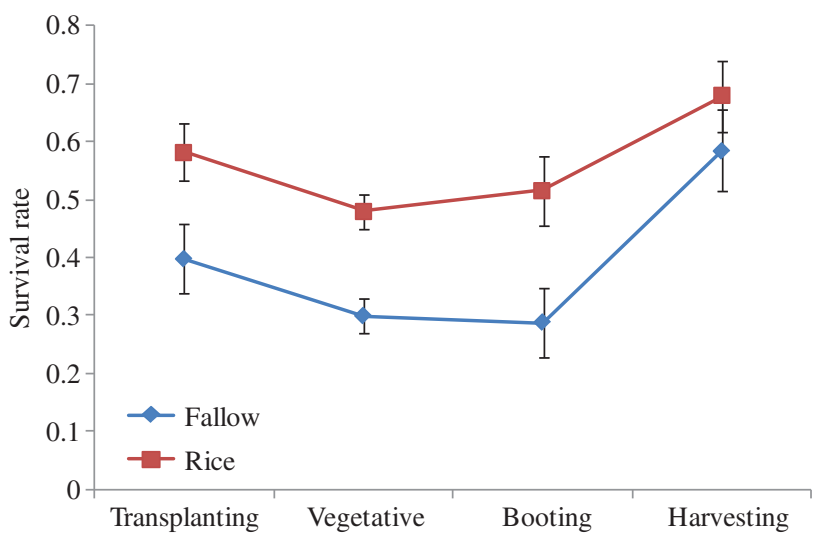

Figure 2: Survival rates $(95 \% \mathrm{Cl})$ of Mastomys natalensis based on the best model (see Table 1) in different habitats and cropping stages.

booting and vegetative stages and the highest was during the harvesting period. In contrast, in the rice fields, the survival rate ranged from 0.48 to 0.67 , which was similarly highest during the harvesting period (Figure 2).

\section{Discussion}

Many pest rodents can survive and reproduce successfully under a fluctuating environment (Massawe et al. 2011, Mulungu et al. 2013), and when conditions change, they can modify their behaviour to suit the new conditions. Therefore, rates of survival and recruitment are necessary components of models that describe and explore the causes of changes in the size of animal populations (Leirs et al. 1994, Massawe et al. 2012). In the present study, it was observed that recruitment of new individuals into the population was higher in the rice fields compared with fallow land. This could be explained by rodents from

Table 1: Model selection for survival $(\Phi)$ and recapture $(P)$ probabilities.

\begin{tabular}{|c|c|c|c|c|}
\hline Model & $\mathrm{AICc}$ & $\Delta \mathrm{AICC}$ & AlCc weights & np \\
\hline$\Phi$ (habitat, cropping stage) $P$ (time) & 3819.75 & 0.00 & 0.77 & 30 \\
\hline$\Phi$ (habitat, time) $P$ (time) & 3829.52 & 3.06 & 0.17 & 65 \\
\hline$\Phi$ (habitat) $P$ (time) & 3837.67 & 11.22 & 0.003 & 24 \\
\hline$\Phi$ (habitat, season) $P$ (time) & 3839.06 & 12.61 & 0.001 & 26 \\
\hline$\Phi$ (constant) $P$ (habitat, time) & 3854.67 & 28.21 & 0.00 & 10 \\
\hline$\Phi$ (habitat) $P$ (time) & 332.36 & 11.69 & 0.002 & 18 \\
\hline$\Phi$ (constant) $P$ (constant) & 3941.33 & 114.87 & 0.00 & 3 \\
\hline
\end{tabular}

The candidate models used to estimate survival in Mastomys natalensis in Tanzania. Estimates of survival $(\Phi)$ and recapture $(P)$ were modelled with time (t) and/or habitat (rice or fallow fields), cropping stage (transplanting, vegetative, booting and harvesting) and season (dry and wet). The number of parameters is indicated by "np". The models are arranged from best (top of table) to worst (bottom). DEV, deviance; $\mathrm{np}$, number of estimable parameters; AICc, Akaike criterion of information corrected for low sample sizes; DAICc, difference in AICc from the model with the minimal score; AW, Akaike's weight. 
surrounding areas being more attracted to the rice field, which was most apparent at transplanting and harvesting time where recruitment was highest. Mulungu et al. (2014) reported that vegetative plant material and seeds were the main types of food consumed by Mastomys natalensis, not only due to their relatively higher abundance in the environments under study but also because of the species' highly specialised herbivorous/granivorous nature. Recruitment was observed to be low at the booting stage, and this could be due more to reasons of seeking shelter, a behaviour which was not measured in this study. In general, it is likely that the variation in recruitment observed in our study is mediated by intra-specific competition for food (rice field) and/or refuge (fallow land), particularly during flooding of the rice fields. Mulungu et al. (2013) reported relatively higher population abundance and density values in fallow land, which may explain the low recruitment values observed in fallow land. Thus, it is likely that the higher densities observed in fallow land lead to intense intra-specific competition and lower recruitment.

In the rice agro-ecosystem used in this study, irrigation is controlled by an irrigation scheme association, with individual farmers having little control over timing and duration of irrigation. As farmers tend to hire land within the irrigation scheme, there can be many fallow fields that remain unused, resulting in a mosaic of rice and fallow habitats. Unfortunately, the ground cover of both habitat types was not precisely measured in this study but is estimated to be around a 50\% split between rice and fallow habitats. Farmers in the study area reported that $53 \%$ of farmers control rodent pests using rodenticides, and $47 \%$ use physical control, e.g., pitfall traps, kill traps, but it is not known whether these efforts have had any marked impact on rodent population dynamics during our study. As most rodent management tends to be ad hoc and uncoordinated (Singleton et al. 2007), we can argue that the rodent management by farmers has probably had little impact on our observations of survival and recruitment.

Although we expected the survival rate for Mastomys natalensis to vary according to time, age and sex, our data did not show any significant changes in survival rates across any of these factors. Various survival models received different levels of support from the data, and the model that received the most support presented survival as a function of habitat and crop growth stage with recaptures dependent on time. One potential explanation for this is that high-quality food resources in rice fields could increase the survival chances of newly born and older animals over the population increase phase. Results from the current study indicated that rice fields had higher survival rates than fallow land, arguably because of enhanced food quality (Leirs et al. 1994, Mulungu et al. 2014). Previous studies have typically shown a negative relationship between the survival of $M$. natalensis and rainfall (Leirs et al. 1997, Julliard et al. 1999). However, this relationship can be complicated by density dependence and whether the population is increasing or decreasing (Sluydts et al.2007). Our study is the first to show an association between survival of $M$. natalensis and habitat type (rice or fallow field). It has been reported that when highquality forage was available, life expectancy of prairie voles increased (Cole and Batzli 1979). It is generally accepted that animals having adequate food and proper nutrition throughout their lives grow larger and remain healthier than animals that experience poor nutrition during part or all of their lives.

Although adult survival in long-lived vertebrate species is a sensitive demographic parameter affecting population change, fecundity is usually more important in species with shorter life spans (Boyce 1992). High adult survival is a life history characteristic that is common to large mammals and vertebrates, in general, but generally not to smaller mammals, including Mastomys natalensis. Wildlife in good condition with higher reproduction rates are more resistant to diseases and can escape predators better than animals in poor condition (Yarrow, 2009). Nutrition affects birth and death rates and is important in the overall survival of any wild animal, and the availability of food usually varies over time (season) and space (geographic location). Observations of high survival in rice fields and particularly during the harvesting period would support the importance of food quality for adult survival (Leirs et al. 1994). Although our study did not collect data on other factors such as disease and predation, our data would suggest that the availability of high quality food is arguably the most important parameter affecting rodent survival in rice/fallow mosaic habitats.

We have demonstrated that survival and recruitment rates of Mastomys natalensis differed with crop growth stage and habitat. The lowest survival and recruitment rates were observed in fallow land, which sustained higher densities of rodents, arguably leading to intense intraspecific competition and, hence, reductions in survival and recruitment. Our results also suggest that high survival and recruitment in rice fields was related to the presence of high quality food that is preferred by M. natalensis (Mulungu et al. 2011). Management strategies should, therefore, be aimed at rodents inhabiting rice fields using methods that reduce recruitment and survival at transplanting and prior to rice maturity. 
Acknowledgments: This work was supported by the Zonal Agricultural Research and Development Funds (ZARDEF) through Eastern Zone. We appreciate the excellent field assistance from Khalid S. Kibwana, Omary Kibwana, Shabani Lutea, Geofrey Sabuni and Ramadhani Kigunguli of Pest Management Centre, Sokoine University of Agriculture, Morogoro, Tanzania. We wish to express our sincere gratitude to the leaders and farmers of Hembeti village for their good cooperation during the course of our field data collection.

\section{References}

Borremans, B., V. Sluydts, R.H. Makundi and H. Leirs. 2014. Evaluation of short-, mid- and long-term effects of toe clipping on a wild rodent. Wildlife Res. http://dx.doi.org/10.1071/WR14109.

Boyce, M.S. 1992. Population viability analysis. Annu. Rev. Ecol. Syst. 23: 481-506.

Burnham, K.P. and D.R. Anderson. 2002. Model selection and multimodel inference. A practical information-theoretic approach, 2nd edition. Springer-Verlag, New York, USA.

Cole, F.R. and G.O. Batzli. 1979. Nutrition and population dynamics of the prairie vole, Microtus ochrogaster, in central Illinois. J. Anim. Ecol. 48: 455-470.

Julliard, R., H. Leirs, N.C. Stenseth, N.G. Yoccoz, K.K.U. Prevotjulliard and J.D. Nichols. 1999. Survival-variation within and between functional categories of the African Multimmamate rat. J. Anim. Ecol. 68: 550-561.

Kennis, J., C. Laurent, N.D. Amundala, A.M. Dudu and H. Leirs. 2012. Survival and movement of the Congo forest mouse (Deomys ferrugineus): a comparison of primary rainforest and fallow land in Kisangani, Democratic Republic of Congo. Afr. Zool. 47: 147-159.

Kingdon, J. 1997. East African mammals: an atlas of evolution in Africa. Vol. 2 part B (Hares and Rodents). Academic Press, London, England. pp. 450.

Lebreton, J.D., K.P. Burnham, J. Clobert and D.R. Anderson. 1992. Modeling survival and testing biological hypotheses using marked animals: a unified approach with case studies. Ecol. Monogr. 62: 67-118.

Leirs, H. 1992. Population ecology of Mastomys natalensis (Smith 1834) multimammate rats: possible implications for rodent control in Africa. PhD Thesis. University of Antwerp, Belgium.

Leirs, H., J. Stuyck, R. Verhagen and W. Verheyen. 1990. Seasonal variation in growth of Mastomys natalensis (Rodentia: Muridae) in Morogoro, Tanzania. Afr. J. Ecol. 28: 298-306.

Leirs, H., R. Verhagen and W. Verheyen. 1994. The basis of reproductive seasonality in Mastomys rat (Rodentia: Muridae). J. Trop. Ecol. 10: 55-66.

Leirs, H., N.C. Stenseth, J.D. Nichols, J.H. Hines, R. Verhagen and W. Verheyen. 1997. Stochastic seasonality and nonlinear densitydependent factors regulate population size in an African rodent. Nature 389: 176-180.
Massawe, A.W., W. Rwamugira, H. Leirs, R.H. Makundi and L.S. Mulungu. 2005. Influence of land preparation methods and vegetation cover on population abundance of Mastomys natalensis in Morogoro, Tanzania. Belg. J. Zool. 135(Sup): 187-190.

Massawe, A.W., L.S. Mulungu, R.H. Makundi, N. Dlamini, S.J. Eiseb, F. Kirsten, T. Mahlaba, P. Malebane, E. von Maltitz, A. Monadjem, P. Taylor, V. Tutjavi and S.R. Belmain. 2011. Spatial and temporal population dynamics of rodents in three geographically different regions in Africa: implication for ecologicallybased rodent management. Afr. Zool. 46: 393-405.

Massawe, A.W., R.H. Makundi, L.S. Mulungu, A. Katakweba and T.N. Shayo. 2012. Breeding dynamics of rodent species inhabiting farm-fallow mosaic fields in Central Tanzania. Afr. Zool. 47: 128-137.

Mulungu, L.S., T.A. Mahlaba, A.W. Massawe, J. Kennis, D. Crauwels, S. Eiseb, A. Monadjem, R.H. Makundi, A.A.S. Katakweba, H. Leirs and S.R. Belmain. 2011. Dietary differences of the multimammate mouse, Mastomys natalensis (Smith 1834), across different habitats and seasons in Tanzania and Swaziland. Wildl. Res. 38: 640-646.

Mulungu, L.S., V. Ngowo, M. Mdangi, A.S. Katakweba, P. Tesha, F.P. Mrosso, M. Mchomvu, P.M. Sheyo and B.S. Kilonzo. 2013. Population dynamics and breeding patterns of Multimammate mouse, Mastomys natalensis (Smith 1834), in irrigated rice fields in eastern Tanzania. Pest Manag. Sci. 69: 371-377.

Mulungu, L.S., E.C.M. Mlyashimbi, V. Ngowo, M. Mdangi, A.S. Katakweba, P. Tesha, F.P. Mrosso, M. Mchomvu, B.S. Kilonzo and S.R. Belmain. 2014. Food preferences of the Multimammate mouse, Mastomys natalensis, in irrigated rice habitats in Tanzania. Int. J. Pest Manag. 60: 1-8.

Odhiambo, R.O., R.H. Makundi, H. Leirs and R. Verhagen. 2005. Community structure and seasonal abundance of rodents of maize farms in southwestern Tanzania. Belgium J. Zool. 135: 113-118.

Pollock, K.H., J.D. Nichols, J.E. Hines and C. Brownie. 1990. Statistical inference for capture-recapture experiments. Wildl. Monogr. 107: 97.

Sikes, R.S. and W.L. Gannon. 2011. Animal Care and Use Committee of the American Society of Mammalogists Guidelines of the American Society of Mammalogists for the use of wild mammals in research. J. Mammal. 92: 235-253.

Singleton, G. R., P.R. Brown, J. Jacob and K.P Aplin. 2007. Unwanted and unintended effects of culling: a case for ecologically-based rodent management. Integr. Zool. 2: 247-259.

Sluydts, V., L. Crespin, S. Davis, M. Lima and H. Leirs. 2007. Survival and maturation rates of the African rodent, Mastomys natalensis: density dependence and rainfall. Integr. Zool. 2: 220-232.

White, G.C. 2008. Closed population estimation models and their extensions in Program MARK. Environ. Ecol. Stat. 15: 89-99.

White, G.C. and K.P. Burnham. 1999. Program MARK: survival estimation from populations of marked animals. Bird Study 46: S120-S138.

Yarrow, G. 2009. Habitat requirements of wildlife: food, water, cover and space http://www.clemson.edu/extension/natural_ resources/wildlife/publications/pdfs/fs14_habitat_requirements.pdf. Visited on 15/09/2014. 